\title{
PERCEPÇÕes DE FORMAdORES DE PROFESSORES E SUAS RELAÇÕES COM O SABER NO CURSO DE LICENCIATURA EM QUímica do INSTITUTO FEDERAL DE GOIÁS
}

\author{
PERCEPTIONS OF TEACHER EDUCATORS AND THEIR RELATIONSHIP WITH \\ KNOWLEDGE IN THE CHEMISTRY DEGREE COURSE AT THE FEDERAL \\ INSTITUTE OF GOIÁS
}

DOI: $10.23926 /$ RPD.2526-2149.2020.v5.n2.p965-981.id679

\section{Ronan Santana dos Santos \\ Doutor em Ensino de \\ Ciências e Educação \\ Matemática (UEL) \\ Professor do Instituto \\ Federal de Goiás (IFG) \\ ronansantos.ifg@gmail.com}

\section{Marinez Meneghello \\ Passos}

Doutora em Educação para a

Ciência (UNESP)

Docente do Programa de

Pós-Graduação em Ensino de

Ciência e Educação

Matemática (UEL)

marinezpassos@uel.br

\section{Sergio de Mello}

Arruda

Doutor em Educação (USP)

Docente do Programa de

Pós-Graduação em Ensino de

Ciência e Educação

Matemática (UEL)

renop@uel.br
Resumo: Neste artigo apresentamos os resultados de uma pesquisa, que teve como objeto de estudo as percepções de formadores de professores e suas relações com o saber. Dessa forma, o objetivo delineado foi o de identificar e analisar como eles elaboravam e constituíam suas relações com o saber. Esta investigação qualitativa se valeu do método indutivo para o cumprimento dos percursos metodológicos. A coleta dos dados foi realizada por meio de entrevistas semiestruturadas, ocorridas virtualmente de dezembro de 2016 a fevereiro de 2017. Foram entrevistados quatro professores do curso de Licenciatura em Química do Instituto Federal de Goiás (IFG). A análise dos dados foi realizada segundo os procedimentos da análise textual discursiva (ATD), utilizando e assumindo como instrumento analítico a Matriz 3x3 e o descritivo de suas células por categorias a priori. Os resultados obtidos revelam elementos sociais, pessoais e epistêmicos nas relações estabelecidas pelos professores pesquisados com o saber.

Palavras-chave: Relações do professor com o saber. Formação de professores. Gestão pedagógica. Matriz 3x3.

\begin{abstract}
In this article we present the results of a research, which had as object of study the perceptions of teacher educators and their relationship with knowledge. Thus, the objective outlined was to identify and analyze how they elaborate and constitute their relations with knowledge. This investigation, whose approach is qualitative, made use of the inductive method to fulfill the methodological paths. Data collection was carried out through semi-structured interviews, carried out virtually from December 2016 to February 2017. Four professors from the Chemistry Degree course at the Federal Institute of Goiás (IFG), campus Anápolis, were interviewed. Data analysis was performed according to the procedures of textual discourse analysis - ATD, using and assuming the $3 \times 3$ Matrix as an analytical instrument, taking into account a priori categories. The results obtained reveal social, personal and epistemic elements in the relationships established by the subject teachers with knowledge.

Keywords: Teacher's relations with knowledge. Teacher training. Pedagogical management. Matrix 3x3.
\end{abstract}




\section{INTRODUÇÃO}

As discussões em torno das relações com o saber do professor há algum tempo estão presentes na literatura dedicada à educação. Autores como Gauthier et al. (2013), Tardif e Lessard (2014), Charlot (2000), Arruda, Lima e Passos (2011), dentre outros, trazem-nos várias reflexões relativas a essas relações docentes com o saber. Saberes esses trazidos da sua época de formação, elaborados segundo suas visões da gestão da matéria e da classe e que convergem para o que acreditam ser função do seu trabalho como docente.

Estas discussões são instigadoras, provocam-nos reflexões intensas, pois é um desafio termos a compreensão sobre "o que acontece quando o professor ensina? [...] o que é preciso saber para ensinar?" (GAUTHIER et al., 2013, p.17).

Pensando nisso, colocamo-nos a investigar o que dizem alguns professores formadores de professores sobre suas relações com o saber. E em uma intenção de compreender essas relações, destacamos que:

\footnotetext{
A atividade docente não é exercida sobre um objeto, sobre um fenômeno a ser conhecido ou uma obra a ser produzida. Ela é realizada concretamente numa rede de interações com outras pessoas, num contexto onde o elemento humano é determinante e dominante e onde estão presentes símbolos, valores, sentimentos, atitudes, que são passíveis de interpretação e decisão que possuem, geralmente, um caráter de urgência (TARDIF, 2003, p.49-50)
}

Dessa forma, compreendendo este universo de interações que a atividade docente estabelece em um ambiente acadêmico, procuramos entrevistá-los tendo como foco estas relações e assumindo que a sala de aula requer do professor o desenvolvimento dessas relações com o saber de forma epistêmica, pessoal e social.

Sendo assim, esta pesquisa teve como objetivo levantar, por meio dos depoimentos de alguns professores formadores de professores do curso de Licenciatura em Química do Instituto Federal de Goiás, campus Anápolis, como eles elaboravam e constituíam suas relações com o saber. Cabe destacar que, em momento posterior, estaremos acompanhando esses professores em suas salas de aula, procurando verificar se as relações indicadas estabelecem-se em suas práticas.

O artigo, aqui exposto, está estruturado em cinco seções: 1) Introdução - em que apresentamos o objeto e o problema de pesquisa, o objetivo traçado e a justificativa para a discussão do tema; 2) As relações do professor com o saber e a Matriz 3x3 - na qual descrevemos a fundamentação teórica do tema central da pesquisa e apresentamos a Matriz 3x3, instrumento de análise dos dados e que aprofunda as discussões sobre a relação do professor com o saber; 3) Percurso metodológico da pesquisa - nesta seção discutimos os procedimentos 
metodológicos assumidos e os caminhos trilhados para o desenvolvimento da investigação; 4) Análise dos dados - é a seção em que inserimos os dados coletados e analisados; 5) Considerações finais - nela argumentamos a respeito das evidências encontradas em função do objetivo investigativo e as conclusões que puderam ser inferidas.

\section{AS RELAÇõES DO PROFESSOR COM O SABER E A MATRIZ $3 \times 3$}

O professor quando está atuando em sala de aula sempre tem, na maioria das vezes, a intencionalidade de fazer com que seu aluno se interesse pelo assunto e aprenda o conteúdo que está ensinando.

Segundo Charlot (2000, p.61):

Não há saber senão para um sujeito, não há saber senão organizado de acordo com relações internas, não há saber senão produzido em uma "confrontação interpessoal". Em outras palavras, a ideia de saber implica a de sujeito, de atividade do sujeito, de relação desse sujeito com ele mesmo (deve desfazer-se do dogmatismo subjetivo), de relação desse sujeito com os outros (que co-constroem, controlam, validam, partilham esse saber) (grifos do autor).

Todavia, o professor necessita conhecer e dominar bem esse assunto que está desenvolvendo. Nesse sentido, a relação com o saber estabelecida por esse professor com o conteúdo, consigo mesmo e com o mundo torna-se fundamental na sua busca pelo ensinar. Para Charlot (2000, p.81):

O conceito de relação com o saber implica o de desejo: não há relação com o saber senão a de um sujeito, e só há um sujeito desejante. Cuidado, porém: esse desejo é desejo do outro, desejo do mundo, desejo de si próprio; e o desejo de saber (ou de aprender) não é senão uma de suas formas, que advém quando o sujeito experimentou o prazer de aprender e saber (grifo do autor).

Isso nos leva a crer que, certamente, há um desejo de saber ou de aprender, mesmo que seja do outro, que é interiorizado pelo professor e colocado em prática nas suas atividades desenvolvidas em sala de aula. Assim, com o objetivo de responder à pergunta "seria possível fundamentar a formação de professores como uma espécie de metáfora a Lacan?", Arruda e Passos (2012) apresentam-nos o conceito de desejo do docente, ou desejo do professor:

Se o desejo do analista, em consideração à formação do mesmo, é um ponto-pivô na Psicanálise, no sentido de fundamentar a ação do psicanalista, não poderíamos pensar em um ponto similar na Formação de Professores (FP)? Algo como o desejo do docente ou desejo do professor? Para ver como ficaria esse conceito na rede conceitual da área de FP, basta transpor as citações (I e II) para este campo. Teríamos:

$\mathrm{I}(\mathrm{t})$ A formação do docente exige que ele saiba, no processo que conduz seu aluno, em torno do que o movimento gira. Esse ponto-pivô é o que eu designo pelo nome de desejo do docente. (transposto a partir de I)

II(t) O desejo do docente, em cada caso, não pode de modo algum ser deixado fora de nossa questão, pela razão de que o problema da formação do docente o coloca. E a docência didática (?) não pode servir para outra coisa senão para levá-lo a esse ponto 
que designo em minha álgebra como o desejo do docente. (transposto a partir de II). (ARRUDA; PASSOS, 2012, p.71-72, grifos nossos).

O que nos leva a considerar que a relação do professor com o saber revela-se na forma de gestão pedagógica, o que Gauthier et al. (2013) denominam por gestão da matéria e gestão da classe.

Dentro de uma proposta semelhante, Tardif (2003) utiliza os termos transmissão da matéria e gestão da interação com os alunos, todavia em suas discussões ficam ocultos os saberes do próprio professor. Fato esse que nos remete à seguinte indagação: como fica a gestão do seu próprio conhecimento, que será um fator essencial na sua atuação em sala de aula?

Segundo Arruda, Lima e Passos (2011, p.143):

\begin{abstract}
Do nosso ponto de vista, pensar que as tarefas essenciais do professor em sala de aula consistem apenas na gestão do conteúdo e na gestão da classe traz pelo menos uma limitação: o professor tem de gerir também a sua própria aprendizagem, o seu próprio desenvolvimento profissional. Tardif e Gauthier parecem ignorar que o professor é uma pessoa e que "uma parte importante da pessoa é o professor" (frase de Jennifer Nias, citada por NÓVOA, 2000, p.15). O professor é uma pessoa cujo desenvolvimento não está incluído entre os "condicionantes". Parece-nos, entretanto, que a tarefa de gerir a si mesmo, sua aprendizagem, sua identidade, seus desejos, seu envolvimento, também deve ser incluída dentre as tarefas que estruturam a ação do professor em sala de aula (grifos dos autores).
\end{abstract}

Assim, esses autores - Arruda, Lima e Passos - procurando redefinir essas relações elaboraram a Matriz 3x3, assumida por eles como a Matriz do Professor (MP), que pode ser observada em Arruda e Passos (2017) em uma versão atualizada, que tem como base as discussões relativas ao sistema didático proposto por Chevallard (2005) e as relações com saber defendidas por Charlot (2000).

A seguir trazemos uma adaptação que fizemos de tal Matriz, a qual foi utilizada na interpretação dos depoimentos dos professores entrevistados, quando interpelados sobre sua forma de planejamento das aulas, suas interações com os alunos e como avaliavam seus alunos e a si próprios.

Quadro 1 - Matriz 3x3

\begin{tabular}{|c|c|c|c|}
\hline $\begin{array}{l}\text { Relações com } \\
\text { o saber }\end{array} \quad \begin{array}{r}\text { Tarefas do } \\
\text { professor }\end{array}$ & $\begin{array}{c}1 \\
\text { Gestão do segmento } \\
\text { P-S } \\
\text { (conteúdo) } \\
\end{array}$ & $\begin{array}{c}2 \\
\text { Gestão do segmento } \\
\text { P-E } \\
\text { (ensino) } \\
\end{array}$ & $\begin{array}{c}3 \\
\text { Gestão do segmento } \\
\text { E-S } \\
\text { (aprendizagem) } \\
\end{array}$ \\
\hline $\begin{array}{c}\text { A } \\
\text { Epistêmica } \\
\text { (conhecimento) }\end{array}$ & $\begin{array}{l}1 \mathrm{~A} \\
\text { Relações epistêmicas } \\
\text { do professor com sua } \\
\text { aprendizagem }\end{array}$ & $\begin{array}{c}2 \mathrm{~A} \\
\text { Relações epistêmicas do } \\
\text { professor com o seu } \\
\text { ensino }\end{array}$ & $\begin{array}{c}3 \mathrm{~A} \\
\text { Relações epistêmicas } \\
\text { do professor com a } \\
\text { aprendizagem dos } \\
\text { estudantes }\end{array}$ \\
\hline $\begin{array}{c}\text { B } \\
\text { Pessoal } \\
\text { (sentido) }\end{array}$ & $1 \mathrm{~B}$ & $2 B$ & $\begin{array}{c}\text { 3B } \\
\text { Relações pessoais do } \\
\text { professor com a }\end{array}$ \\
\hline
\end{tabular}




\begin{tabular}{|c|c|c|c|}
\hline & $\begin{array}{c}\text { Relações pessoais do } \\
\text { professor com sua } \\
\text { aprendizagem }\end{array}$ & $\begin{array}{c}\text { Relações pessoais do } \\
\text { professor com o seu } \\
\text { ensino }\end{array}$ & $\begin{array}{c}\text { aprendizagem dos } \\
\text { estudantes }\end{array}$ \\
\hline $\begin{array}{c}\text { Social } \\
\text { (valor) }\end{array}$ & $\begin{array}{c}\text { Relações sociais do } \\
\text { professor com sua } \\
\text { aprendizagem }\end{array}$ & $\begin{array}{c}\text { Relações sociais do } \\
\text { professor com o seu } \\
\text { ensino }\end{array}$ & $\begin{array}{c}\text { Relações sociais do } \\
\text { professor com a } \\
\text { aprendizagem dos } \\
\text { estudantes }\end{array}$ \\
\hline
\end{tabular}

Fonte: Arruda, Lima e Passos (2011, p.147-148),

Em nossa pesquisa, a Matriz $3 \times 3$ foi utilizada como instrumento analítico com o propósito de elaborar a compreensão das relações com o saber estabelecidas por esses professores formadores. Cada uma de suas novas células (1A, 1B, 1C, 2A, 2B, 2C, 3A, 3B, 3C) que descrevem essas relações, foi assumida como categorias a priori. Diversos esclarecimentos sobre esse processo estão expostos na próxima seção.

\section{Percurso metodológico da Pesquisa}

As pesquisas na área de educação cada vez mais se apoderam da abordagem qualitativa que garante caminhos transparentes e capazes de revelar os dados obtidos e analisá-los de maneira consistente e flexível.

De acordo com Bogdan e Biklen (1994, p.47-50), a investigação qualitativa possui cinco características que merecem ser consideradas:

1. A fonte direta de dados é o ambiente natural, constituindo o investigador o instrumento principal; [...] 2. A investigação qualitativa é descritiva; [...] 3. Os investigadores qualitativos interessam-se mais pelo processo do que simplesmente pelos resultados ou produtos; [...] 4. Os investigadores qualitativos tendem a analisar os seus dados de forma indutiva; [...] 5. O significado é de importância vital na abordagem qualitativa.

Levando em conta essas características, destacamos que nossa pesquisa constituiu-se como qualitativa, valendo-se do método indutivo, que perpassa os caminhos metodológicos trilhados, com o intuito de descrever e compreender como se desenvolvem as relações com o saber dos formadores de professores do curso de Licenciatura em Química no IFG, campus Anápolis.

A coleta de dados da pesquisa, de caráter naturalista ou de campo, conforme indicam Fiorentini e Lorenzato (2006), foi realizada por meio de entrevistas semiestruturadas, que ocorreram como "um encontro entre duas pessoas, a fim de que uma delas obtenha informações a respeito de determinado assunto, mediante uma conversação de natureza profissional" (LAKATOS, 1993, p.195-196 apud SZYMANSKI; ALMEIDA; PRANDINI, 2008, p.10). 
As entrevistas foram realizadas no período em que os docentes estavam em férias (dezembro de 2016 a fevereiro de 2017) e para isso utilizamos a rede social WhatsApp como ferramenta para contato e realização das conversas.

Encerradas as entrevistas, iniciamos o processo de transcrição, que foi realizado sem uso de software, e na íntegra com todas as respostas dos sujeitos da pesquisa. Trazemos partes dessas entrevistas transcritas na continuidade do artigo, sendo que cada um dos quatro professores adotou um critério para suas respostas. Destacamos ainda que os trechos omitidos neste artigo dizem respeito a outros assuntos que não as discussões relativas às relações com o saber que buscávamos evidenciar e organizar.

Com a intenção de manter o anonimato dos entrevistados utilizamos os códigos P1, P2, P3 e P4 para identificar os quatro sujeitos. Com relação às suas áreas de formação e atuação, o professor P1 estava doutorando na área da Química Orgânica; o professor P2 estava doutorando na área de Ensino de Química; o professor P3 estava doutorando na área de Ensino de Ciências e o professor P4 já havia concluído o doutorado em Matemática.

Inicialmente, fizemos uma breve explicação do tema que seria abordado e, em seguida, começamos a entrevista apresentando a eles uma pergunta de cada vez. Destacamos que foi dado o tempo necessário para cada professor responder à indagação, que, posteriormente, era retomada pelos pesquisadores, e, que quando necessário, havia uma devolutiva de esclarecimento ou então era apresentada uma nova questão.

Para os quatro entrevistados foram feitas três perguntas que denominamos de 'principais', e, conforme esclarecido, se necessário, eram formuladas outras. As perguntas focavam o planejamento de suas aulas, a interação com alunos em sala de aula e os processos avaliativos adotados por eles.

Cabe relembrar que os entrevistados ficaram livres para responder da forma que achassem melhor, inclusive retomando questões e respostas já relatadas, alterando a ordem do que foi exposto.

A análise dos dados considerou os procedimentos da análise textual discursiva (ATD) que "transita entre duas formas consagradas de análise na pesquisa qualitativa que são a análise de conteúdo e a análise de discurso" (MORAES; GALIAZZI, 2006, p.118).

Segundo Moraes (2003), esta abordagem organiza os argumentos em quatro focos: a unitarização; a categorização; o metatexto; o processo auto-organizado. Os três primeiros fecham um ciclo de análise, denominado pelo autor de "tempestade de luz" (MORAES, 2003). 
No último foco - pautado na auto-organização do processo - o objetivo é o de emergir novas compreensões.

Com base nesses pressupostos teóricos para discussão dos dados e de posse do corpus $^{1}$ que compõe o material obtido com os depoimentos, analisamos as entrevistas realizadas com os quatro professores do IFG do campus Anápolis, que atuavam ou tinham atuado no curso de Licenciatura em Química nos últimos dois anos.

\section{ANÁLISE dOS DADOS}

Vamos apresentar os relatos escolhidos na transcrição das falas de cada um dos quatro docentes P1, P2, P3 e P4, seguido das alocações na Matriz 3x3 daquele professor e, por fim, uma discussão a respeito do que pudemos evidenciar com essa distribuição nas células do instrumento.

Professor P1: Os números de (1) a (13), que antecedem os excertos deste depoimento, dizem respeito às unidades de registro que foram alocadas posteriormente na Matriz 3x3 (ver Quadro 2, a seguir). Tais unidades estão relacionadas ao contexto defendido por cada uma das células do instrumento elaborado por Arruda, Lima e Passos (2011), o qual nos traz subsídios para compreender as relações com o saber estabelecidas por P1.

(1) O planejamento do ponto de vista de conteúdo, eu sempre tento organizar primeiramente as ideias, de modo a tentar facilitar a organização das ideias dos alunos. (2) Então, em termos de organização da sala de aula, do espaço físico da sala de aula, a forma como os alunos estão é a forma como eu conduzo. (3) As disciplinas que eu trabalho, tanto no ensino médio quanto no superior têm relação com Química orgânica, então têm muitas partes da Química orgânica que a gente tem que pensar em modelos, em como transpor aquilo que eu tô falando na forma de modelos. (4) Então, para determinados conteúdos sempre tem uma estratégia que eu penso que seria melhor para aquele determinado conteúdo. (5) Não faço esse planejamento antes e converso com eles na medida em que surge a necessidade. Se eu vejo que tem muita conversa, que está atrapalhando, então eu faço uma conversa com os alunos naquele momento, mas é algo que é de acordo com a necessidade mesmo, e se for necessário. (6) Sempre tenho em mente, quando você fala em desenvolvimento da aula, o que um professor de estágio meu falou na época da graduação ainda, ele falava assim: uma aula bem estruturada do ponto de vista dele é uma aula que você começa falando do que você vai falar, você fala o que tem que falar, e depois recapitula o que você acabou de falar. (7) Com relação ao desenvolvimento da aula, pensando no ponto de vista da classe, da sala, eu tento sempre manter interação mesmo. Então, sempre fazendo a conversa com os alunos, tentando chamar a atenção deles pra aquilo que eu estou falando. Tento sempre fazer a interação para ver se eu ganho a atenção deles pro que eu tô falando. A interação no sentido de fazer perguntas no meio da aula mesmo, e tentar buscá-los para participação junto daquilo que estou falando. (8) Eu vejo a prova como um momento mesmo de avaliar o trabalho que foi feito ali, durante o semestre,

\footnotetext{
${ }^{1} \mathrm{O}$ conjunto dos documentos tidos em conta para serem submetidos aos procedimentos analíticos (BARDIN, 2004, p.90).
} 
durante o bimestre. (9) Enfim, e fico frustrada mesmo quando as notas são baixas, porque alguma falhou ali no meio do processo. (10) Com relação à construção do pensamento e à evolução dos alunos nessas avaliações, onde eu consigo perceber mais essa evolução é no formato dos relatórios das aulas práticas. (11) Acho difícil falar de avaliação em termos da sala, da classe, porque não é um critério que eu levo em consideração. (12) Como eu falei, sou bastante tradicional nesse sentido e o que eu uso como avaliação são as provas e relatórios mesmo. (13) Mesmo na licenciatura eu trabalho muito lista de exercícios com os alunos, mas essas listas não são voltadas para a nota. São listas que a gente vai trabalhando durante o desenvolvimento do conteúdo que eu sempre reservo uma aula antes da prova pra fazer a correção dessas listas e pra tirar as eventuais dúvidas que os alunos têm. Mas são listas mesmo com caráter de estudo, não seria de caráter avaliativo.

Quadro 2 - Indícios das relações com o saber de P1

\begin{tabular}{|c|c|c|c|}
\hline $\begin{array}{l}\begin{array}{l}\text { Relações } \\
\text { com o saber }\end{array} \\
\begin{array}{r}\text { Tarefas do } \\
\text { professor }\end{array}\end{array}$ & $\begin{array}{c}1 \\
\text { Gestão do segmento } \\
\text { P-S } \\
\text { (conteúdo) }\end{array}$ & $\begin{array}{c}2 \\
\text { Gestão do segmento } \\
\text { P-E } \\
\text { (ensino) }\end{array}$ & $\begin{array}{c}3 \\
\text { Gestão do segmento } \\
\text { E-S } \\
\text { (aprendizagem) }\end{array}$ \\
\hline $\begin{array}{c}\mathbf{A} \\
\text { Epistêmica } \\
\text { (conhecimento) }\end{array}$ & (3) & $(1) ;(4) ;(6) ;(12) ;(13)$ & (10) \\
\hline $\begin{array}{c}\begin{array}{c}\text { B } \\
\text { Pessoal } \\
\text { (sentido) }\end{array} \\
\end{array}$ & & (8); (11) & (9) \\
\hline $\begin{array}{c}\text { C } \\
\text { Social } \\
\text { (valor) }\end{array}$ & & $(2) ;(5)$ & (7) \\
\hline
\end{tabular}

Fonte: Os autores (2017).

Podemos observar o Quadro 2 de várias maneiras: linha a linha; coluna a coluna; suas células vazias; as células com maior frequência.

Diante de tantas possibilidades decidimos focar, primeiramente, a coluna central, aquela que diz respeito ao ensino que o professor pratica e que tem o maior número de alocações. P1 tem sua formação na área 'dura' de Química e está atuando recentemente na licenciatura. É interessante notar que a célula 2A destaca sua relação epistêmica com o ensino, seguida de suas considerações pessoais e sociais sobre este mesmo segmento. Todavia, ele também demonstra preocupações com relação aos alunos no decorrer das suas aulas, tanto na dimensão epistêmica quanto na pessoal e social.

Ao observarmos linha a linha essas acomodações fica evidente a predominância do ponto de vista epistêmico em suas falas, o que nos remete à seguinte consideração de Charlot (2000, p.70): “O sujeito epistêmico é o sujeito afetivo e relacional, definido por sentimentos e emoções em situação e em ato".

Professor P2: Os números de (14) a (36), que antecedem os excertos do depoimento descrito a seguir, dizem respeito às unidades de registro que foram alocadas na Matriz $3 \times 3$ do professor 


\section{P2. Utilizamos a numeração em continuidade em função de acomodações e considerações} conclusivas apresentadas no final desta seção do artigo.

(14) Questão do planejamento que eu como professora penso, ele é imprescindível para qualquer atividade que você vai desenvolver na sala de aula. (15) Então, eu penso que o planejamento tem que ser um planejamento primeiro por parte do professor, (16) que tem que adentrar à sala com uma visão do que ele vai trabalhar durante aquele semestre, mas ele é passível de modificações ao longo do processo. Não pode ser amarrado. (17) Quando eu falo que o planejamento é imprescindível inicialmente, falo no sentido em que acho importante apresentar para os alunos esse planejamento, por exemplo, no primeiro dia de aula. (18) Porque também eu acho que ele pode ser construído coletivamente com os alunos. (19) Agora, por exemplo, estava programada uma avaliação, mas eu não posso retornar depois de três meses parados e dar uma avaliação. (20) Hoje eu conversei com a turma e a gente já retirou essa avaliação. (21) Vou avaliar basicamente por meio das atividades que a gente estava fazendo e aí a gente vai ter uma atividade avaliativa que vai ser um seminário no final da disciplina. (22) Mas tudo foi combinado conjuntamente ali. Então eu ouvi as partes, ouvi o que os meninos queriam me dizer com relação a isso. (23) Eles até foram para uma discussão que saiu até da disciplina, que era uma discussão mais política, da questão da ocupação, que eles avaliaram que a ocupação não foi legal, que prejudicou, que o direito deles não foi ouvido. Porque do mesmo jeito que os meninos tiveram o direito de ocupar eles também tinham o direito de vir para a escola e ter as aulas. (24) A gente caminhou até para uma questão política, que não estava prevista na disciplina, então eu esperei, com muita calma, escutei os alunos. (25) E eu acho que o conteúdo em si de algumas disciplinas, e aí eu posso dizer da maioria das disciplinas que eu ministro na licenciatura tem um pouco disso, dessa carga teórica, então ficaria muito exaustivo. (26) Quando penso num determinado conteúdo e escolho o material que vai ao encontro desse conteúdo específico, tento sempre pensar uma estratégia metodológica para aquela determinada aula, (27) para que ela seja conduzida da melhor maneira possível, para que o aluno também tenha condições de fixar aquele conteúdo que vai ser trabalhado naquela aula. (28) Na primeira aula a gente discute a importância que eles façam as leituras. Então a leitura é imprescindível, (29) mas eu nunca me prendo ao fato de que eles realmente vão fazer a leitura. Eu sempre tento ter um plano B, porque se eu chego na sala de aula naquele determinado dia que o combinado era que os alunos lessem o texto e eu percebo que eles não leram, então eu tenho um plano B. (30) A gente não consegue esgotar cada conteúdo. Isso é uma ilusão. Por mais que eu queira, que eu desejo né, um texto, que eu sempre faço anotações comigo, que acho importante discutir sobre aquele determinado tema, a gente não consegue esgotar ele, justamente porque em todas as aulas, em algum momento, existe esse desvio. (31) Os alunos geralmente, a gente escuta as conversas nos corredores, ah essas disciplinas pedagógicas, que é assim que eles chamam né, essas são de boa. (32) Então, para não tentar banalizar, apesar de todas as teorias, e tudo mais, eu costumo avaliar, pelo menos uma avaliação, (33) porque como a gente tem textos, tem teorias, têm referenciais teóricos que embasam todas as discussões feitas na sala de aula, então eu considero, também né, que como eu falei, o exercício da escrita é muito importante, mas o aluno tem que estar bem fundamentado, ele não pode ficar só no achismo. (34) E, no final da disciplina, eu costumo também fazer uma avaliação da disciplina; essa avaliação é importantíssima demais pra mim, né, porque ela, de certa forma, faz com que eu possa melhorar ainda mais essa disciplina no próximo semestre. (35) Então, os próprios alunos dão um feedback, de onde eu posso melhorar, o que eles acham que faltou na disciplina, que de repente precisa discutir mais, aprofundar mais. (36) Então eu acredito, nesse sentido, que apesar da gente não garantir uma aprendizagem efetiva com relação aos conteúdos, porque isso, infelizmente, eu não consigo, é impossível pra eu captar se realmente o aluno teve essa aprendizagem efetiva, mas se ele modificou a sua postura, se ele modificou a sua visão, né, em outros momentos lá na frente do curso se eu vou ter a possibilidade de encontrar com esse aluno novamente, então já valeu a pena demais. 
Quadro 3 - Indícios das relações com o saber de P2

\begin{tabular}{|c|c|c|c|}
\hline $\begin{array}{c}\text { Tarefas do } \\
\text { professor } \\
\text { Relações } \\
\text { com o saber }\end{array}$ & $\begin{array}{c}\mathbf{1} \\
\text { Gestão do segmento } \\
\text { P-S } \\
\text { (conteúdo) }\end{array}$ & $\begin{array}{c}\mathbf{2} \\
\text { Gestão do segmento } \\
\text { P-E } \\
\text { (ensino) }\end{array}$ & $\begin{array}{c}\mathbf{3} \\
\text { Gestão do segmento } \\
\text { E-S }\end{array}$ \\
\hline $\begin{array}{c}\text { A } \\
\text { Epistêmica } \\
\text { (conhecimento) }\end{array}$ & $(26)$ & $\begin{array}{c}(14) ;(16) ;(17) ;(19) ; \\
(21) ;(29) ;(32) ;(33)\end{array}$ & $(31)$ \\
\hline $\begin{array}{c}\text { B } \\
\text { Pessoal } \\
\text { (sentido) }\end{array}$ & $(25)$ & $(15) ;(30) ;(34)$ & \\
\hline $\begin{array}{c}\text { C } \\
\text { Social } \\
\text { (valor) }\end{array}$ & & $(18) ;(20) ;(22) ;(23) ;(27) ;(36)$ & \\
\hline
\end{tabular}

Fonte: Os autores (2017).

Observando a Matriz de P2, notamos uma grande incidência na gestão do segmento P-E, relativo ao ensino. Diferentemente de P1, sua formação foi totalmente voltada para a licenciatura, para o ensino de Química. E, mesmo assim, ele mantém suas preocupações com o ensinar, intensificada na linha epistêmica, depois na social e, por fim, com menor intensidade na pessoal.

Cabe destacar que P2 fazia um planejamento geral e cotidiano para a elaboração de suas aulas, sempre tomando o cuidado de ter o que ele denominava de "plano B", em virtude dos constantes descumprimentos dos alunos em não fazerem as leituras previamente indicadas.

A leitura horizontal, ou seja, linha a linha da Matriz, revela-nos certo equilíbrio quantitativo entre as três relações com o saber, com uma quantidade maior para a epistêmica, seguida da pessoal e, por último, a social. Isso nos leva a inferir que as relações com o saber deste docente estavam 'equilibradas', fato que nos remete ao seguinte destaque de Charlot (2000, p.80): “A relação com o saber é o conjunto (organizado) das relações que um sujeito mantém com tudo quanto estiver relacionado com o aprender e o saber" (grifos do autor).

Professor P3: Os números de (37) a (55), que antecedem os excertos deste depoimento que se segue, dizem respeito às unidades de registro inseridas na Matriz 3x3 do professor P3.

(37) A gente tem a nota única no ensino superior, mas eu planejo primeiro o curso, colocar de maneira geral, depois de maneira mais específica. Primeiro o curso, assim, apresentando esse contrato didático para os alunos, de como vai ser todo o processo avaliativo. (38) Então, assim, pormenorizo lá o conteúdo que vai sendo trabalhado e faço naquela primeira aula um prelúdio disso. E falo pra eles assim, até porque a gente pode, depois de quinze dias mais ou menos, entregar o plano definitivo. (39) Tenho feito isso com as turmas do ensino superior que ministro aula, que é colocar um ambiente virtual, seja o moodle, ou qualquer outro, geralmente o moodle, como uma plataforma de apoio ao ensino presencial. (40) E aí colocar algumas atividades por lá também. Fiz uma atividade que achei interessante no semestre passado, com os alunos 
da engenharia, e pretendo fazer com outras turmas do ensino superior, por exemplo, a Química também. (41) Por exemplo, nas aulas experimentais eu procuro não dar um roteiro pronto para eles seguirem; (42) costumo dar um problema pra eles e a partir desse problema eles vão coletando dados e a partir dessa coleta eles vão percebendo uma certa regularidade nesses dados para a partir daí confirmar uma lei. (43) Às vezes a gente acaba caindo numa linha mais tradicional, enfim, porque às vezes até não tem tanto tempo para planejar uma aula, e acaba indo para uma proposta mais tradicional. (44) Alguns alunos às vezes gostam da ideia de você colocar um problema em si, mas quando você coloca o problema e espera a resposta deles, um fala isso, outro fala aquilo, aí eles respondem e você lança uma nova pergunta em cima, mas e aí, como que é? (45) Pra tentar captar a visão prévia que estão tendo, muitos alunos não gostam da demora disso, acham assim, aquele professor não vai direto ao ponto, está enrolando. Eles têm um pouco essa concepção, esse vai e volta é meio que enrolar, enfim, isso às vezes tem um pouco que gerir. (46) De fato tenho uma preocupação muito grande com a aprendizagem do aluno. (47) Eu percebo que alunos que chegam bem preparados, no sentido de ter tido uma formação em termos de conteúdo, sólida, outros que estão num nível intermediário, outros que chegam com muita dificuldade. (48) Muitas vezes em momentos até extraclasse, ou muitas vezes assim, alguma informação que até a própria coordenação de apoio ao discente passa para a gente assim, sabe, algumas situações de vulnerabilidade social do aluno também, que justifica alguma coisa. (49) Não no sentido de cair assim, num discurso político/ideológico sobre isso, não é essa a ideia. (50) Mas assim, de ver de onde o aluno está partindo, tenho uma preocupação social de ver de onde ele está partindo. (51) Mas, enfim, de maneira mais pormenorizada assim, eu procuro a princípio conhecer isso, mas com o propósito de saber do conhecimento prévio dele, o grande propósito é esse. (52) Já pensando assim, em avaliação também, eu penso que fui muito influenciado na disciplina que fiz no mestrado, sobre a avaliação (Luchesi), primeiro contato que eu tive com avaliação foi essa. (53) Procuro sempre partir dessa ideia de avaliação qualitativa. Se o aluno tirou dois e dez, ele evoluiu para dez. (54) Por exemplo, seja um conteúdo que não altera tanto, por exemplo, física I, não altera tanto, mas o planejamento é outro porque os personagens são outros, os alunos são outros, e para cada realidade eu rasgo o plano antigo e faço outro. (55) E às vezes um outro plano dentro do curso mesmo. Isso é uma coisa que eu procuro fazer e tenho gostado dos resultados disso. Às vezes mais na Química do que na Engenharia.

Quadro 4 - Indícios das relações com o saber de P3

\begin{tabular}{|c|c|c|c|}
\hline $\begin{array}{ll}\begin{array}{l}\text { Relações } \\
\text { com o saber }\end{array} & \begin{array}{c}\text { Tarefas do } \\
\text { professor }\end{array} \\
\end{array}$ & $\begin{array}{c}1 \\
\text { Gestão do segmento } \\
\text { P-S } \\
\text { (conteúdo) }\end{array}$ & $\begin{array}{c}2 \\
\text { Gestão do segmento } \\
\text { P-E } \\
\text { (ensino) }\end{array}$ & $\begin{array}{c}3 \\
\text { Gestão do segmento } \\
\text { E-S } \\
\text { (aprendizagem) }\end{array}$ \\
\hline $\begin{array}{c}\mathbf{A} \\
\begin{array}{c}\text { Epistêmica } \\
\text { (conhecimento) }\end{array}\end{array}$ & & $\begin{array}{c}(37) ;(38) ;(39) ;(40) ; \\
(41) ;(42) ;(43) ;(54) ; \\
\quad(55)\end{array}$ & $\begin{array}{c}(46) ;(47) ;(50) ;(51) ; \\
\text { (53) }\end{array}$ \\
\hline $\begin{array}{c}\begin{array}{c}\text { B } \\
\text { Pessoal } \\
\text { (sentido) }\end{array} \\
\end{array}$ & & (49) & $(45) ;(48)$ \\
\hline $\begin{array}{c}\mathrm{C} \\
\text { Social } \\
\text { (valor) }\end{array}$ & (52) & (44) & \\
\hline
\end{tabular}

Fonte: Os autores (2017)

A Matriz de P3 traz maior predominância na gestão do ensino, seguida da gestão E-S, a aprendizagem, mostrando uma preocupação destacada para a aprendizagem que os outros dois professores P1 e P2 não enfatizaram. 
Cabe lembrar que a formação de P3 foi centrada na Licenciatura em Física. Por meio do teor de seus depoimentos, é possível evidenciar um grande comprometimento com os alunos, principalmente, no que diz respeito à aprendizagem, procurando ainda conhecer detalhes da vida dos estudantes, entre eles, os motivos pessoais relacionados aos desempenhos ruins nos estudos.

Quando fazemos uma leitura linha a linha do Quadro 4, observamos uma grande incidência nas relações epistêmicas com o saber, volume este bem maior que nos entrevistados P1 e P2, principalmente, no setor 3A da Matriz, aquele destinado aos excertos que focam a preocupação em suas aulas com a aprendizagem dos alunos. O que nos remete ao seguinte destaque: “Aprender sempre é entrar em uma relação com o outro, o outro fisicamente presente em meu mundo [...] Toda relação com o saber comporta, pois, uma dimensão relacional, que é parte integrante da dimensão identitária" (CHARLOT, 2000, p.72). As relações com o saber para P3 (quando observamos suas argumentações) constituem-se por meio de um entrelaçamento entre o ensino e a aprendizagem, mostrando-se indissociáveis.

Professor P4: Os números de (56) a (72) estão relacionados aos excertos do depoimento de P4, e, também, mantendo o nosso padrão de apresentação foram inseridos na Matriz 3x3.

(56) Então, a questão do planejamento, vamos pensar no planejamento do conteúdo. Então assim, sempre que a gente vai começar um novo curso, uma nova disciplina, ou mesmo que seja uma repetida, que trabalhei alguma vez, primeiramente dou uma olhada boa na ementa, e tento procurar umas bibliografias que encaixem dentro daquela ementa. (57) Dou uma procurada geral dentro do que a gente tem do Instituto Federal, na nossa biblioteca, quanto às que não têm. Tem uma em PDF, alguns sites que disponibilizam, ou mesmo na UFG, caso haja necessidade. A ideia é buscar primeiro a bibliografia. (58) Tem tema que em matemática que é bastante visual, dá para a gente trabalhar com coisas sólidas, ou mesmo em softwares. (59) Ultimamente tenho utilizado bastante softwares, com gráficos e desenhos, de maneira geral. (60) Hoje em dia graças à informática a gente tem esse poder de usar esses softwares com bastante sofisticação que é muito visual, quando é necessário. (61) Tem partes de disciplinas que não são tão visuais assim, mesmo matemática que não tem visual, mas mesmo assim a gente busca um aspecto de um rascunho, alguma coisa para apresentar de forma mais clara para os alunos. (62) Sempre nas primeiras aulas eu tento identificar mais ou menos a turma, identificar mais ou menos como ela funciona, é claro que não dá pra saber nas primeiras aulas, mas a gente vai começando testando, vai tentando identificar como tá o pessoal em relação ao assunto. (63) Tem disciplina que exige pré-requisito então a gente vai dando uma analisada, vê como eles tratam esse pré-requisito, e aí tentar desenvolver de uma forma mais tranquila. (64) Em aspectos formais da sala, de formação e tudo, de ambiente de sala eu costumo ser o mais liberal possível nesse sentido. (65) Então assim, uma ou outra pessoa que não pôde estar no dia da prova, justificado antes, geralmente já deixo fixo a próxima aula depois, ou faz a prova ou então espero reunir todos que não fizeram para ter uma conversa com eles pra marcar um novo dia, por exemplo, costuma ser o padrão. (66) Como é bem liberal nesse sentido não costumo deixar isso explícito no começo, isso 
vai depender de cada turma. (67) A aula em si, digamos assim, desenvolve de uma maneira mais simples possível. (68) Digamos que dentro das primeiras aulas eu chego e vou batendo um papo com o pessoal, tentando compreender um pouquinho de cada um ali, um pouquinho de como eles veem as coisas, (69) e digamos no caso de um conteúdo, por exemplo, que já tem um conteúdo em mente, eu tento dar uma extraída um pouquinho do que eles já têm alguma opinião a respeito daquilo, de maneira geral, e aí vai. (70) Geralmente quando a pessoa fica alheia, isso é estatística, no geral não está fluindo, um ou outro não tem dificuldade nenhuma, mas no geral, quando a pessoa se cala muito é que não está fluindo. (71) E há momentos que eu deixo mais livre, pensando assim, na gestão da classe, há momentos que está mexendo com algum exercício, eles podem ter umas conversas paralelas, mas na verdade elas são interessantes, para que eles consigam desenvolver e naturalmente não exijo aquele silêncio absoluto da sala. (72) Avaliação sempre é um problema, é uma coisa que a gente sempre tem que analisar muito, sempre tem dúvida. Mas percebo na avaliação o seguinte, tento descobrir se o aluno conseguiu compreender a essência do curso, se ele sabe analisar vários termos, várias coisas, assim, dentro da vida que a pessoa tem, juntamente com elementos do curso.

Quadro 5 - Indícios das relações com o saber de P4

\begin{tabular}{|c|c|c|c|}
\hline $\begin{array}{l}\begin{array}{l}\text { Relações } \\
\text { com o saber }\end{array} \\
\begin{array}{c}\text { Tarefas do } \\
\text { professor }\end{array}\end{array}$ & $\begin{array}{c}1 \\
\text { Gestão do segmento } \\
\text { P-S } \\
\text { (conteúdo) }\end{array}$ & $\begin{array}{c}2 \\
\text { Gestão do segmento } \\
\text { P-E } \\
\text { (ensino) }\end{array}$ & $\begin{array}{c}3 \\
\text { Gestão do segmento } \\
\text { E-S } \\
\text { (aprendizagem) }\end{array}$ \\
\hline $\begin{array}{c}\text { A } \\
\text { Epistêmica } \\
\text { (conhecimento) }\end{array}$ & $(56) ;(57)$ & $\begin{array}{c}(59) ;(60) ;(61) ;(65) ; \\
(69) ;(72)\end{array}$ & $(62) ;(63) ;(70)$ \\
\hline $\begin{array}{c}\text { B } \\
\text { Pessoal } \\
\text { (sentido) }\end{array}$ & (58) & (67) & \\
\hline $\begin{array}{c}\text { C } \\
\text { Social } \\
\text { (valor) }\end{array}$ & & $(64) ;(66) ;(68) ;(71)$ & \\
\hline
\end{tabular}

Fonte: Os autores (2017)

Assim como os demais entrevistados, as alocações dos comentários de P4 incidiram com maior frequência na coluna 2 - na relação com o ensino - com ênfase na linha epistêmica, o que nos revela sua preocupação com o ensino que pratica em sala de aula. Contudo, P4 destaca, nos depoimentos, suas habilidades em negociar com os alunos.

Apesar de ter em sua formação uma pós-graduação em Matemática, P4 consegue dialogar com seus alunos com a intenção de promover um ambiente apropriado para o ensino, mostrando-se pouco preocupado com a aprendizagem. Essa sua habilidade corrobora com o que Charlot (2000, p.73) nos apresenta: "Uma aula interessante é uma aula na qual se estabeleça, em uma forma específica, uma relação com o mundo, uma relação consigo mesmo e uma relação com o outro".

Em uma leitura horizontal, o que percebemos das acomodações dos depoimentos de P4 é o mesmo que já evidenciamos com a análise dos outros três professores, uma incidência maior na dimensão epistêmica em sua relação com o saber. 
O retrato do que obtivemos diante do que os entrevistados nos colocaram pode ser observado no Quadro 6 inserido na sequência.

Quadro 6 - Indícios das relações com o saber dos quatro professores

\begin{tabular}{|c|c|c|c|c|}
\hline $\begin{array}{l}\text { Relações } \\
\text { com o saber }\end{array} \begin{array}{c}\text { Tarefas do } \\
\text { professor }\end{array}$ & $\begin{array}{c}1 \\
\text { Gestão do } \\
\text { segmento } \\
\quad \text { P-S } \\
\text { (conteúdo) } \\
\end{array}$ & $\begin{array}{c}2 \\
\text { Gestão do } \\
\text { segmento } \\
\text { P-E } \\
\text { (ensino) }\end{array}$ & $\begin{array}{c}3 \\
\text { Gestão do segmento } \\
\text { E-S } \\
\text { (aprendizagem) }\end{array}$ & $\begin{array}{c}\text { Totais } \\
(\%)\end{array}$ \\
\hline $\begin{array}{c}\text { A } \\
\text { Epistêmica } \\
\text { (conhecimento) }\end{array}$ & $(3) ;(26) ;(56) ;(57)$ & $\begin{array}{l}(1) ;(4) ;(6) ;(12) ; \\
(13) ;(14) ;(16) ; \\
(17) ;(19) ;(21) ; \\
(29) ;(32) ;(33) ; \\
(37) ;(38) ;(39) ; \\
(40) ;(41) ;(42) ; \\
(43) ;(54) ;(55) ; \\
(59) ;(60) ;(61) ; \\
(65) ;(69) ;(72)\end{array}$ & $\begin{array}{c}(10) ;(31) ;(46) ;(47) ; \\
(50) ;(51) ;(53) ;(62) ; \\
(63) ;(70)\end{array}$ & $58 \%$ \\
\hline $\begin{array}{c}\text { B } \\
\text { Pessoal } \\
\text { (sentido) } \\
\end{array}$ & $(25) ;(58)$ & $\begin{array}{c}(8) ;(11) ;(15) ; \\
(30) ;(34) ;(49) ; \\
(67)\end{array}$ & $\begin{array}{c}(9) ;(24) ;(27) ;(36) ; \\
(45) ;(48)\end{array}$ & $21 \%$ \\
\hline $\begin{array}{c}\mathrm{C} \\
\text { Social } \\
\text { (valor) }\end{array}$ & $(52)$ & $\begin{array}{l}\text { (2); (5);(18);(20); } \\
\quad(22) ;(23) ;(28) ; \\
(35) ;(44) ;(64) ; \\
(66) ;(68) ;(71)\end{array}$ & (7) & $21 \%$ \\
\hline Totais & $1 \%$ & $66 \%$ & $23 \%$ & $100 \%$ \\
\hline
\end{tabular}

Fonte: os autores (2017)

Fazendo uma leitura horizontal do Quadro 6 observamos que 58\% (42) das unidades de registro incidiram na linha $\mathrm{A}$, ou seja, as relações com o saber demonstradas pelos sujeitos da pesquisa foram essencialmente do tipo epistêmicas. Em uma leitura vertical vemos que $66 \%$ (48) das unidades de registro incidiram na coluna central. A concentração dos depoimentos na coluna relativa ao ensino nos remete à preocupação intensificada desses professores com o que eles faziam em sala de aula, em detrimento do que os seus alunos estavam aprendendo (coluna 3), um resultado já encontrado em outros trabalhos. Observa-se também que a célula $2 \mathrm{~A}$ destaca-se com um quantitativo superior às demais (39\% ou 28 unidades). Em resumo, isso demonstra que estes professores do IFG desenvolviam suas ações em sala de aula em uma perspectiva epistêmica priorizando o seu ensino em relação ao conteúdo e à aprendizagem.

O sujeito epistêmico é, então, o sujeito encarnado em um corpo, entendendo-se por isso, no caso, não um sistema de órgãos distintos da "alma", mas, sim, o corpo tal como foi definido por Merleau-Ponty. O corpo é um lugar de apropriação do mundo, um "conjunto de significações vivenciadas", um sistema de ações em direção ao mundo, aberto às situações reais, mas, também, virtuais. [...] Existe, de fato, um Eu, nessa relação epistêmica com o aprender, mas não é o Eu reflexivo que abre um universo de saberes-objetos, é um Eu imerso em uma dada situação, um eu que é corpo, percepções, sistema de atos em um mundo correlato de seus atos (como 
possibilidade de agir, como valor de certas ações, como efeito dos atos) (CHARLOT, 2000, p.69, grifos do autor).

Dessa forma, as relações epistêmicas presentes nas aulas dos professores entrevistados fundamentavam-se nos seus ensinamentos sempre com uma atenção para desenvolvimento de uma boa aula.

\section{CONSIDERAÇÕES FINAIS}

A intenção desta investigação foi a de mapear e procurar compreender quais eram as relações com o saber, estabelecidas por professores formadores do IFG do campus Anápolis, que atuavam ou tinham atuado nos últimos dois anos no curso de Licenciatura em Química.

Para tal evidenciação fizemos uso de um instrumento denominado Matriz $3 \times 3$ que, segundo seus proponentes, auxilia na compreensão de alguns fenômenos relativos aos fazeres dos professores. Em especial naquilo que diz respeito: ao conteúdo da disciplina que ministram, ao ensino que praticam, ao aprendizado de seus alunos, tudo isso observado segundo as dimensões epistêmicas, pessoais e sociais.

Alguns professores revelaram inquietações e incertezas quanto à forma de avaliar, indicando que as fragilidades deste processo eram contornadas por meio do diálogo, da ampliação dos "tipos" de instrumentos avaliativos, da rediscussão dos processos, dando novas oportunidades, tentando escapar das burocracias e das normas que complexificavam o trabalho docente. Diante dessas considerações apontadas pelos professores, retomamos Tardif e Lessard (2014, p.41, grifos nossos), quando destacam que "pode-se também considerar os componentes informais da atividade (docente), aqueles aspectos que estão implícitos ou 'invisíveis' no ofício e suas inúmeras contingências, imprevistos, ou seja, as áreas flutuantes que revelam sua complexidade".

Outro aspecto que nos chamou a atenção ao final da acomodação dos excertos dos quatro docentes foi o fato de que todas as células da Matriz foram preenchidas, mesmo que duas delas, $1 \mathrm{C}$ e 3C, por apenas uma fala. Isso nos coloca diante de uma situação satisfatória, pois ao considerar que uma proposta ideal de relações com o saber seria aquela que mapeasse todos os setores deste instrumento, esses professores que atuavam nesta Licenciatura em Química complementaram um ao outro suas deficiências e habilidades.

De acordo com as análises feitas, utilizando a Matriz 3x3, pudemos concluir que os quatro professores entrevistados consideraram o ensino como elemento prioritário nas preparações de suas aulas e, principalmente, nas atuações em sala de aula. Dessa forma, 
estabelecem a relação com o saber do ponto de vista dos seus ensinamentos, voltados para os aspectos epistêmicos - o conhecimento.

$\mathrm{O}$ aspecto da aprendizagem dos alunos foi menos priorizado, ficou em segundo plano, mas, também, com uma preponderância da relação com o saber no aspecto epistêmico, ou seja, a aprendizagem não se mostrou tão relevante do ponto de vista pessoal e, menos ainda, do ponto de vista social.

Finalmente, foi observado que os professores entrevistados priorizavam menos as relações com o conteúdo. Isto nos faz concluir que estes educadores não se preocupavam com as relações com os conteúdos que iriam ministrar, talvez pelo fato de se sentirem totalmente ou quase totalmente preparados em discutir os assuntos que ensinariam.

\section{REFERÊNCIAS}

ARRUDA, Sergio de Mello; LIMA, João Paulo Camargo; PASSOS, Marinez Meneghello. Um novo instrumento para a análise da ação do professor em sala de aula. Revista Brasileira de Pesquisa em Educação em Ciências, [s. l.], v.11, n.2, p.139-160, 2011.

ARRUDA, Sergio de Mello; PASSOS, Marinez Meneghello. Da psicanálise ao ensino de ciências: o "desejo do docente" e o "professor como um lugar". Revista Ciência \&

Educação, Bauru, v.18, n.1, p.69-80, 2012.

ARRUDA, Sergio de Mello; PASSOS, Marinez Meneghello. Instrumentos para a análise da relação com o saber em sala de aula. REPPE - Revista do Programa de Pós-Graduação em Ensino, Cornélio Procópio, v.1, n.2, p.95-115, 2017.

BARDIN, Laurence. Análise de conteúdo. 3. ed. Lisboa: Edições 70, 2004.

BOGDAN, Robert C.; BIKLEN, Sari Knopp. Investigações qualitativas em educação: uma introdução à teoria e aos métodos. Tradução Maria João Avarez, Sara Bahia dos Santos, Telmo M. Baptista. Portugal: Porto Editora, 1994.

CHARLOT, Bernard. Da relação com o saber: elementos para uma teoria. Tradução Bruno Magne. Porto Alegre: Artmed, 2000.

CHEVALLARD, Yves. La transposición didáctica: del saber sabio al saber enseñado. Buenos Aires: Aique Grupo Editor, 2005.

FIORENTINI, Dario; LORENZATO, Sérgio. Investigações em educação matemática: percursos teóricos e metodológicos. Campinas: Autores Associados, 2006.

GAUTHIER, Clermont; MARTINEAU, Stéphane; DESBIENS, Jean-François; MALO, Annie; SIMARD, Denis. Por uma Teoria da Pedagogia: pesquisas contemporâneas sobre o saber docente. 3. ed. Ijuí: Unijuí, 2013.

MORAES, Roque. Uma tempestade de luz: a compreensão possibilitada pela análise textual discursiva. Ciência \& Educação, Bauru, v.9, n.2, p.191-211, 2003. 
MORAES, Roque; GALIAZZI, Maria do Carmo. Análise Textual Discursiva: processo reconstrutivo de múltiplas faces. Ciência \& Educação, Bauru, v.12, n.1, p.117-128, 2006.

SZYMANSKI, Heloisa; ALMEIDA, Laurinda Ramalho de; PRANDINI, Regina Célia Almeida Rego. A entrevista na pesquisa em educação: a prática reflexiva. Brasília: Liber Livro Editora, 2008.

TARDIF, Maurice. Saberes docentes e formação profissional. 3. ed. Petrópolis: Vozes, 2003.

TARDIF, Maurice; LESSARD, Claude. O trabalho docente: elementos para uma teoria da docência como profissão de interações humanas. 9. ed. Petrópolis: Vozes, 2014.

Recebido em: 6 de maio de 2020.

Aprovado em: 16 de julho de 2020. 